\title{
NARRADORES DE JAVÉ E A PESQUISA EM EDUCAÇÃO
}

\author{
Cristiane Ludwig* \\ Amarildo Luiz Trevisan ${ }^{* *}$
}

\section{RESUMO}

O texto propõe uma hermenêutica sobre os paradoxos criados pelo paradigma da relação sujeito/objeto, problematizando a absolutização da subjetividade moderna na produção do conhecimento e suas implicações na formação de professores. Nesse contexto, demarca os contornos e as deficiências localizadas na recepção das abordagens qualitativas e quantitativas nas pesquisas em educação. Para elucidar essas questões, este estudo utiliza a narrativa, Narradores de Javé, por intermédio da abordagem hermenêutico-reconstrutiva, como exercício do reconhecimento do saber da alteridade. A hermenêutica quer desvendar as armadilhas do caminho metafísico do conhecimento na formação de professores e provocar nos interlocutores envolvidos o estranhamento das práticas pedagógicas enrijecidas pelo paradigma unilateral do mundo moderno.

Palavras-chave: Formação de professores. Hermenêutica. Pesquisas qualitativas.

\section{ABSTRACT}

The paper proposes a hermeneutics on the paradoxes created by the paradigm of subject/object relationship, questioning the absolutism

\footnotetext{
* Doutoranda do Programa de Pós-Graduação em Educação do CE/UFSM. Membro do Grupo de Pesquisa Formação Cultural, Hermenêutica e Educação (GPFORMA). E-mail: crisludwig@yahoo.com.br

** Doutor em Educação pela Universidade Federal do Rio Grande do Sul (UFRGS). Professor dos Cursos de Licenciatura e do Programa de Pós-Graduação em Educação (Mestrado e Doutorado) da Universidade Federal de Santa Maria (UFSM). Bolsista de Produtividade em Pesquisa (PQ) do CNPq. E-mail: amarildoluiz@terra.com.br
} 
of modern subjectivity in knowledge production and its implications for teacher training. In this context, it determines the outlines and deficiencies underlying the reception of qualitative and quantitative approaches in educational research. To clarify these issues, this work was based on the narrative Narradores de Javé, making use of the hermeneuticreconstructive approach, as an attempt to recognize the knowledge of otherness. Hermeneutics seeks to unveil the pitfalls of the path of metaphysical knowledge in teacher training and cause, in the interlocutors involved, some estrangement regarding the teaching practices hardened by the unilateral paradigm of the modern world.

Keywords: Qualitative researches. Hermeneutic. Teaching.

\section{Considerações iniciais sobre a Pesquisa em Educação}

A manifestação das abordagens qualitativas no campo educacional possibilitou a ampliação de perspectivas e novos olhares para o sujeito da educação. No âmbito acadêmico, os estudos apontam para um movimento de rejeição do modelo positivista nas pesquisas em educação. Isso porque no paradigma positivista existe uma realidade exterior ao sujeito que pode ser conhecida objetivamente. Nesse protótipo, os fenômenos são analisados de forma fragmentada e explicados por meio de relações de causa e efeito, amplamente generalizáveis, deixando de lado o singular, o diferente, o que não se encaixa no modelo. Além disso, o positivismo busca independência entre sujeito e objeto e neutralidade no processo de investigação.

Da crítica ao modelo positivista surge o reconhecimento da abordagem qualitativa nas pesquisas em educação. Tais abordagens abrem caminho para a subjetividade, os valores, os contextos, as diferenças, as questões sociais (culturais, políticas, econômicas), antes esquecidas no modelo positivista. As pesquisas qualitativas aparecem como forma de evitar o tecnicismo e o reducionismo do modelo objetificador em favor da valorização da subjetividade. Além disso, enquanto os positivistas buscam independência entre sujeito e objeto e neutralidade no processo de investigação, para os qualitativos, conhecedor e conhecido estão em contínua interação. 
No entanto, estudos da área apontam parauma apropriação superficial e equivocada da abordagem qualitativa nas pesquisas em educação. As pesquisas de Gouveia (1971, 1976); Gatti (1983); Cunha (1979, 1991); Mello (1983) e Warde (1990), segundo levantamento de Alves-Mazzotti (2001), advertem que o crescente prestígio das abordagens qualitativas nas pesquisas em educação não tem sido, na prática, acompanhado pela utilização adequada de metodologias que permitam lidar com o problema proposto, tendo em vista a sua falta de "rigorosidade" nas investigações. As avaliações e os diagnósticos dessas pesquisas focalizam que os problemas e as deficiências das pesquisas em educação estão inter-relacionadas.

A pobreza teórico-metodológica identificada nas pesquisas parece ser, em grande parte, responsável pela sua pulverização e irrelevância e, também, pela adesão aos modismos e pela preocupação com a aplicabilidade imediata dos resultados (ALVES-MAZZOTTI, 2001, p. 41).

Gatti (2002) identifica que a crítica ao modelo quantitativo se assenta na perspectiva dogmática que esse modelo conduz, na crença da verdade absoluta e generalizada, na neutralidade e objetividade das intervenções, nas relações lineares, passivas e acríticas. Contudo, a autora denuncia que essa crítica, nem sempre fruto de reflexão de um conhecedor, teve uma adesão fraca, aligeirada e pouco consistente também em relação aos procedimentos qualitativos, redundando em trabalhos meramente descritivos. Os diagnósticos indicam uma utilização mecânica, ritualística ou formal dos meios de investigação, próximo aos esquemas das ciências experimentais, com interpretações à luz de uma abordagem teórica desarticulada dos procedimentos adotados e realizados. E complementa: "Se criticou-se que os métodos estatísticos deixavam de lado o singular, o diferente, o que não se encaixava no modelo, coerentemente tem-se que exercitar a mesma crítica com relação a qualquer perspectiva teóricometodológico" (GATTI, 2002, p. 55). Lincoln e Guba (apud ALVES, 1991) observam que, assim como o pesquisador tradicional se preocupa com a validade, generalidade, fidedignidade e objetividade de seu design, o pesquisador qualitativo planeja seu estudo de modo a obter credibilidade, transferibilidade, consistência e confirmabilidade. 
Isso remete a compreensão de que em cada tradição de análise, seja a lógico-empirista ou materialista histórica, ou a fenomenológica, ou outra ainda, para além da forma de abordagem, há um conjunto de crenças, valores, atitudes em relação ao modo de perceber e tratar os fenômenos e o próprio conhecimento. Enquanto conhecimentos aproximativos não são dogmas, são conhecimentos orientadores por um tempo, sempre revisáveis ou superáveis, nas áreas humanas, dada a vitalidade interativa do homem com os outros e com o mundo.

Descontextualizadas e transplantadas sem raízes, as teorias descaracterizam-se ou viram dogmas. Perdem, portanto, sua condição de verdade aproximada e relativa, de síntese provisória, a ser revista, discutida e superada pela pesquisa consistente e crítica, dentro de uma apropriada tradição investigativa (GATTI, 2002, p. 45).

A ausência de critérios de demarcação consensuais e o abandono das falsas certezas prometidas pelo modelo tradicional de ciência revelam uma considerável desorientação por parte dos pesquisadores, que esbarra, em grande medida, no vale-tudo. Se, de um lado, essa desorientação parece compreensível, de outro, vemos que o relativismo, que se alastra no campo das pesquisas em educação, não tem contribuído para a ampliação de conhecimentos relevantes e confiáveis para orientar políticas e práticas educacionais (ALVES-MAZZOTTI, 2001, p. 48). As deficiências ou ainda a falta de rigorosidade nas pesquisas em educação se encontram na apropriação descuidada pelos próprios pesquisadores. Nessa direção, Devechi e Trevisan (2009) alertam para o esquecimento do objeto nas pesquisas em educação ou ainda para a perda do conteúdo da crítica ampliada - seja em relação à esfera cultural, econômica, política, ideológica.

O corretivo possível ou alternativo para as deficiências e os limites localizados na recepção das abordagens qualitativas e quantitativas, nas pesquisas em educação, indicam que o retoque pode acontecerpelo respaldo da observação rigorosa dos princípios ou normas da interpretação hermenêutica objetiva de caráter reconstrutivo. Nessa abordagem, o intérprete considera tanto o sentido latente ou objetivo, por exemplo, de uma expressão, texto, 
imagem ou fotografia, como o seu sentido subjetivo ou intencional. Para tanto, a hermenêutica objetiva apoiou-se, por um lado, na teoria crítica da Escola de Frankfurt, e, por outro, na teoria da linguagem de George Herbert Mead, no conceito de regra (rules) de John Searle e no princípio lógico da abdução de James Peirce, conforme Reichertz (apud WELLER ${ }^{1}$, (2007). Interessa para a discussão esclarecer que a falsa oposição entre qualitativo e quantitativo ou a falta de rigorosidade científica nas pesquisas qualitativas não é consequência das abordagens qualitativas em si, mas sim das suas indevidas utilizações (DEVECHI; TREVISAN, 2009), ou ainda, uma questão de ênfase e não de exclusividade (ALVES, 1991).

\section{O exercício hermenêutico-reconstrutivo a partir dos Narradores de Javé}

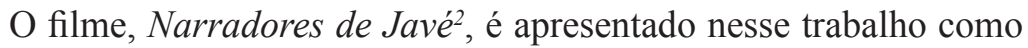
tentativa de exercício da abordagem hermenêutico-reconstrutiva. $\mathrm{O}$ filme narra a história do povoado de Javé, que será submerso pelas águas de uma grande hidrelétrica. Os moradores do vilarejo, sem possibilidade de serem indenizados nem sequer notificados, já que não possuem registros ou documentos das terras, descobrem que o local poderia ser preservado se tivesse um patrimônio cultural de valor comprovado em "documento científico". Diante da notícia, a comunidade decide colocar em prática a escritura do dossiê, documentando o que consideram ser os "grandes" e "nobres" acontecimentos da história do povoado e, assim, justificar a sua existência. A maioria dos moradores de Javé são bons contadores de histórias, mas, no entanto, mal sabem escrever o próprio nome, ou seja,

\footnotetext{
${ }^{1}$ Não é pretensão do trabalho delinear uma descrição exaustiva e detalhada dessa abordagem e os argumentos para a validade da interpretação e elaboração de resultados objetivos sobre o objeto estudado. Para isso, o leitor pode pesquisar o texto de Wivian Weller, que enumera os princípios ou normas de interpretação da hermenêutica objetiva descritos por Wohlrab-Sahr (2003).

${ }^{2} \mathrm{O}$ elenco do filme conta com importantes nomes do cinema nacional como José Dumont, Matheus Nachtergaele, Nelson Xavier e Nelson Dantas. Narradores de Javé foi eleito o melhor filme do Festival do Rio, segundo o júri popular e o oficial. O melhor filme e melhor roteiro no $3^{\circ}$ Festival Internacional do Filme Independente de Bruxelas. A direção é de Eliane Caffé.
} 
são analfabetos. O único adulto alfabetizado de Javé é Antônio Biá (José Dumont), incumbido de recuperar a história e transpor para o papel de forma "científica" as memórias dos moradores. O artifício de inventar fatos escritos sobre os moradores já era usado por Biá para aumentar a circulação de cartas, escassas no povoado, e, com isso, manter em funcionamento a agência de correio em que trabalhava. Por inventar esses episódios, Biá é expulso da cidade. Escrever a história de Javé e tentar preservar seu patrimônio cultural é a oportunidade de apaziguar sua relação com a comunidade de Javé. Para isso, ele terá a permissão de ouvir e registrar os relatos mais importantes que formarão a trama histórica do vilarejo. Uma tarefa difícil porque nem sempre os habitantes concordam sobre qual, dentre todas as versões, deverá prevalecer na memória do povoado. $\mathrm{Na}$ construção deste dossiê, inicia-se uma disputa entre os contadores e de suas histórias, muitas vezes fantásticas e lendárias, sobre o direito de registrarem o patrimônio cultural de Javé. Entre a multiplicidade de versões que repercutem nas falas, a arbitrariedade da interferência e a necessidade de produzir algo convincente para salvar Javé, Biá entrega um livro em branco para o povoado. Ao final, pressionado pela população, Biá sai atormentado do vilarejo.

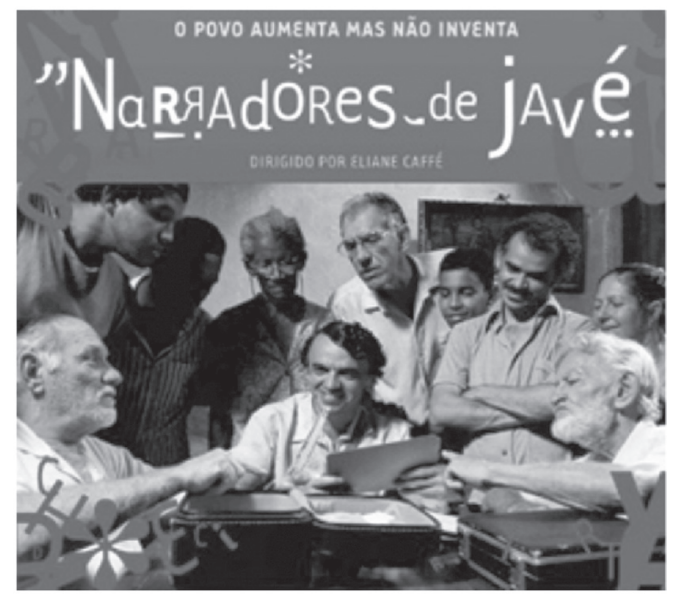

FIGURA 1 - DVD Narradores de Javé Fonte: Encarte do DVD Narradores de Javé 
Para organizar o dossiê, a população adota como metodologia as narrações, no caso, as histórias dos acontecimentos que ocorreram na cidade de Javé. Contar histórias dos acontecimentos no mundo perpassa as experiências humanas as quais podemos atribuir um sentido, porque dizem respeito aos sujeitos e a sua inserção no mundo. Seria possível, por exemplo, narrar uma história sobre alguma descoberta das ciências naturais, se perguntássemos pelo significado que essa teve para as pessoas. Para além da socialização dos conhecimentos, que, por si só, significa uma importante investida formativa, é possível ainda indagar em que medida esse faz ou pode vir a fazer parte do espaço intersubjetivo, transposto para uma linguagem que possibilita a comunicação e o pensar sobre ele, entre outras questões. Nesse caso, não se trata de uma linguagem abstrata acessível somente aos especialistas, mas de palavras que possam falar da relevância dessa descoberta ou desse conhecimento para o mundo humano e para as pessoas que o constitui. Desse modo, o vilarejo de Javé, além de uma informação geográfica, um registro histórico ou ainda um lugar propício para a instalação da represa, poderia ainda fazer referência da existência das pessoas que vivem nele.

Aargumentação se aproxima ao conteúdo defendido pelas abordagens qualitativas, que aparecem justamente para dar conta do lado não perceptível e não captável das abordagens quantitativas com seu uso de medidas e procedimentos estatísticos. Ou seja, as abordagens qualitativas emergem para mostrar que o procedimento fundamentado apenas no modelo objetivante é insuficiente para pensar a formação do sujeito social. A justificativa pode ser articulada da fórmula pensada pela população de Javé como o possível valor comprovado em "documento científico" para preservar seu povo da extinção do vilarejo. Isso na medida em que a população buscava com esse recurso mostrar o valor da subjetividade existente naquele local, que seria, com a vinda da represa, inundada pelo rio.

No entanto, é justamente a disputa entre qual das versões que deveria compor o documento cientificamente comprovado que impossibilitou estabelecer acordos entre os sujeitos envolvidos, que acabaram por desviar o foco para esse aspecto somente. Ou seja, não buscaram um consenso perante uma comunidade de argumentação dos interesses gerais aglutinados, permanecendo na aceitação das pretensões individuais de 
cada um, o que fere uma abordagem hermenêutico-reconstrutiva, visto que se desenvolve pelo descentramento do sujeito que precisa se justificar ao outro. Nesse caso, a negociação, que é um tipo de diálogo de troca entre os interlocutores, poderia ter sido utilizada pela população de Javé. O êxito desse tipo de diálogo ocorre quando surge um acordo, o que pressupõe saber ouvir, de modo a superar as próprias limitações. O diálogo exige a participação dos envolvidos, expondo as próprias posições sobre conceitos e pré-conceitos. Desse modo, um diálogo que não oblitera em dificuldades pressupõe que o participante esteja aberto para mudar a própria posição e entrar no jogo com o outro. "O outro passa a ser a categoria central das pesquisas, pois Habermas neste ponto é fiel aos pressupostos da teoria crítica como consciência aguda da negação da alteridade" (DEVECHI; TREVISAN, 2009).

Nesse sentido, a atitude da população, restrita unicamente aos próprios interesses, pode ser consequência de uma formação frágil ou até de uma ausência formativa mais ampla, ou seja, faltou um "preparo", um reconhecimento do saber da alteridade, pois não acolheram o outro para a construção do documento. A carência de um projeto intersubjetivo significou para a população de Javé a perda dos referenciais comuns e a possibilidade de preservar o vilarejo. Certamente seria pretensioso afirmar que projetos formativos solucionariam os problemas dos moradores de Javé, até porque não há garantias de que seus fins sejam atingidos. Contudo, isso evidencia que metas formativas são indispensáveis à nossa existência, por mais discutíveis que sejam.

A figura de Biá também chama a atenção para essa discussão em sua insistência em aclamar: "minha gente, vamos aos fatos". A expressão evidencia a preocupação do escrivão em preconizar que o tipo de conhecimento correto é o conhecimento científico provado, desmerecendo qualquer outro tipo de conhecimento como pré ou anticientífico, como se as subjetividades ali existentes, não significassem ou ainda, não protagonizassem o cenário científico. A atitude do escrivão não leva em consideração que nosso conhecimento tem raízes na prática das relações pré-científicas, pré-reflexivas que mantemos com as coisas e as pessoas, o que nos permite encontrar outros possíveis sentidos para nosso agir no mundo. Ao contrário, no filme, o escrivão busca transportar os princípios 
e as regularidades das ciências duras para as histórias da população de Javé, assumindo a neutralidade frente aos fatos e a unidade do método, tal como um pesquisador positivista. Em contrapartida, numa abordagem hermenêutico-reconstrutiva, o pesquisador assume como pressuposto a análise das crenças pelo reconhecimento público. Os significados resultam de acordos estabelecidos entre os interlocutores que precisam estar abertos e levar a sério a posição do outro, questionado as ideias e as opiniões tidas como lógicas e naturais. Nessa perspectiva, a investigação apreende a compreensão pela reflexão intersubjetiva dos problemas do mesmo mundo.

O sentido, contudo, não cabe em definições. Ele sempre tem algo de incapturável que escapa a qualquer conceituação o que, de certa forma, dá razão ao escrivão nas suas inúmeras fugas, toda vez que era forçado a escrever o sentido trazido por cada um na sua história. É, portanto, impossível dizer o sentido, de modo que não podemos simplesmente informar os alunos a respeito dele. É, no entanto, possível comunicar significados. A narrativa, como Narradores de Javé, interpretada hermeneuticamente nesse texto, pode ser um modo de fazê-lo. Ao narrar ocorrências e fatos, o que não significa aprová-los, mas sim torná-los humanamente compreensíveis, nos provoca a estabelecer relações com eles, que, por sua vez, careceu para a população de Javé.

$\mathrm{O}$ professor enquanto narrador do mundo ao mostrar sua participação (direta ou indireta) nessas experiências, provoca os alunos a buscarem sua maneira de se relacionar com o mundo. Na interação, somos desafiados a descobrir nossa singular pertença no mundo sem perder de vista a preocupação com o outro, condição imprescindível na tarefa de renovar um mundo comum a todos, inclusive para os moradores de Javé.

\section{A Hermenêutica na Formação de Professores}

No projeto intitulado "A Crise da Educação e o AutoEsclarecimento Hermenêutico na Formação dos Professores3",

3 Projeto em desenvolvimento no Curso de Doutorado, na Linha de Pesquisa: Formação, Saberes e Desenvolvimento Profissional - Temática: Racionalidade Docente e Mundo da Vida, do Programa de Pós-Graduação em Educação - Centro de Educação, da 
tematizamos algumas configurações e exigências teóricas para a formação de professores na contemporaneidade, reconhecendo na linguagem um horizonte intransponível de ampliação do conhecimento para as relações pedagógicas. As problematizações da crise na educação norte-americana identificadas por Hannah Arendt evidenciam a perda dos referenciais comuns ocasionada pelo mundo moderno, enfraquecendo o discurso teórico em detrimento do conhecimento vitalizado na ação. Na pesquisa buscamos questionar os limites rígidos estabelecidos no âmbito das teorias pedagógicas, denunciando o caráter excludente do conceito que não reconhece o outro e não acolhe aquilo que escapa às suas determinações.

É nesse aspecto que encontramos pontos que convergem para um mesmo sentido com as questões levantadas no filme, isto é, o resgate ou a recuperação das experiências vividas sem os "óculos" dos formalismos, sejam científicos ou pseudo-científicos, positivistas ou pós-positivistas. A fim de diluir os paradoxos criados pelo paradigma da relação sujeito/objeto, buscamos na pesquisa aprofundar os conceitos filosóficos na formação de professores, problematizando a produção do conhecimento nos moldes empíricos da busca da verdade absoluta. Nas pesquisas qualitativas não existem verdades que podem se impor sobre os fatos, como se fosse possível desrespeitar uma tradição que em si mesma já é plural. Em relação ao filme, compreendemos que não houve consenso entre os sujeitos envolvidos, no caso a população de Javé, pois cada um impôs a sua verdade, que no fundo era a sua própria versão dos fatos. As lições de Hannah Arendt, que denuncia a tendência da modernidade de impor uma fórmula única para o processo educacional, alertam para o risco de igualar características naturais, físicas. Esse limite pode ser atingido quando forem eliminados os extremos das desigualdades da condição econômica e educacional. No entanto, nessa conjuntura surge um ponto crítico:

quanto mais iguais as pessoas se tornam em todos os aspectos, e quanto mais igualdade permeia toda a textura da sociedade, mais

Universidade Federal de Santa Maria. Nesse trabalho, pretendemos aprofundar alguns tópicos no âmbito de interesse da formação de professores, considerando alguns referenciais teóricos extraídos da obra Entre o Passado e o Futuro, de Hannah Arendt, especialmente do seu artigo "A Crise na Educação". 
as diferenças provocarão ressentimento, mais evidentes se tornarão aqueles que são visivelmente e por natureza diferentes dos outros (ARENDT, 2004, p. 268).

A preocupação da autora se volta para os problemas da redução dos seres humanos plurais a um único homem. Nesse invólucro os homens vão sendo modelados como que em série, assumindo uma única forma. $\mathrm{O}$ artifício homogeneizador pode representar, no processo pedagógico,um fator estacionário, fragilizando os horizontes formativos da educabilidade humana. Os riscos da absolutização de padrões podem afetar não só os projetos formativos que consideram as individualidades, como também aqueles destinados a sociedades inteiras, como ocorreu, por exemplo, nos campos de concentração.

É por conta dessas questões que buscamos apoio na hermenêutica que se articula em torno da crítica ao distanciamento alienante provocado pela racionalidade instrumental, reduzindo a formação de professores aos ditames da cientificização, em que o outro se torna objetivado em mera conformidade rígida por meio de princípios metódicos. Nos sistemas formativos, a concepção técnico-científica tem produzido o avanço da burocratização, o predomínio da racionalidade instrumental e uma humanização pouco consistente. Do ponto de vista de Hermann (2002), as diferentes versões do olhar objetivador, seja behaviorismo, tecnicismo ou construtivismo, deixam escapar a experiência dos atores envolvidos no processo, com seus inevitáveis danos e preconceitos, e, por consequência, empobrecem a experiência formativa.

Nas pesquisas qualitativas a relação sujeito/objeto é acolhida sob novo enfoque, dada a exclusividade da objetividade preconizada pelo positivismo. Uma importante compreensão desse processo acontece com a superação da absolutização da subjetividade moderna no processo de conhecimento, no sentido do domínio do sujeito. Gadamer (1996), opondo-se a mentalidade científica moderna, que limitou a verdade ao campo do cientificismo, objetivando e relegando as experiências do momento histórico, enfatiza a necessidade do resgate da historicidade da compreensão presente na tradição cultural e na linguagem, como tentativa de promover a fusão de horizontes da interpretação. Gadamer propõe, por 
um lado, a hermenêutica como contradição entre método (científico) e a verdade, ou seja, não acredita em um método de compreensão. Por outro, como recuperação de sentido, isto é, não se trata de um método científico no sentido moderno, mas de um caminho do pensamento imerso na história. $\mathrm{O}$ intérprete não pode escapar da história, pois esta é a condição da verdade.

A instauração da linguagem se apresenta como possibilidade de superação da dicotomia positivista entre sujeito e objeto. A experiência humana é linguageira e a participação em uma tradição depende da possibilidade de interpretação dos signos, das obras, dos textos em que está inscrita a herança da trajetória cultural que se oferece à nossa decifração. O significado não é uma propriedade existente desde um ponto de vista objetivo e nem de uma projeção subjetiva. Ele emerge na relação das coisas em si mesmas com as crenças e valores do intérprete situado na história. Para Gadamer (1983), a situação hermenêutica inclui o sujeito conhecedor dentro do processo de conhecimento e transforma o processo de compreender em uma perigosa aventura em que não há garantias, pois sua tarefa é infinita. A experiência educativa, enquanto hermenêutica, se lança para situações abertas e inesperadas, o que coincide com a impossibilidade de assegurar ações pedagógicas numa estrutura estável, que busque o êxito da prática interventiva.

Ampliando o leque da abordagem, Habermas propõe uma hermenêutica que se utiliza do processo de reflexão. O autor não dispensa a questão do método nas ciências humanas, pois aposta na sua recolocação no processo intersubjetivo de reflexão. Sua abordagem aponta para a ideia de universalidade, por meio de um telos presente na linguagem que promova a comunicação por meio da instância performativa voltada ao entendimento mútuo. Nessa proposta, a linguagem é uma comunicação conforme regras que possibilitam o consenso e salvam situações de entendimento perturbado. Habermas (1990) esclarece que o enfoque performativo, do agente que se orienta pelo entendimento, pode ser diferenciado conceitualmente do enfoque objetivador, do agente que se orienta para o sucesso, se lançarmos mão dos modos de nos referirmos ao mundo, os quais admitem os dois enfoques. $\mathrm{Ou}$ seja, por meio de nossas ações de fala nós nos referimos, simultaneamente, mediante tematizações alternantes, a algo no mundo objetivo, subjetivo e social; teleologicamente, nós só podemos intervir no mundo objetivo. 
Os apontamentos do autor permitem indicar que o enfoque da linguagem performativa fornece a ampliação do sentido da experiência humana situada em um círculo hermenêutico, que reconhece a alteridade do outro, não se fechando em pontos de vista cognitivos e normativos. Nesse sentido, a formação do professor, possibilitado pela tradição, age em direção contrária à do reducionismo técnico, que não consegue ser fundador de sentido. Para Hermann, a superação da dissociação entre o mundo moderno e o "eu", com seus problemas de incomunicabilidade e desvinculação, pela via da compreensão, pode tanto fundamentar o distanciamento do "eu", da singularidade que vivencia emoções, quanto criar as condições reflexivas para a produção de um mundo comum.

Conceitos fundamentais como o de "círculo hermenêutico" mostram que em todos os nossos procedimentos racionais projetamos pontos de vista, esquemas interpretativos, que irão de fundir com novos horizontes de sentidos, não mais horizontes particulares, mas parte de uma comunidade de compreensão, o que possibilita compartilhar simbolizações, lealdades e expectativas comuns. Com essa experiência o sujeito percebe que está limitado por seus próprios preconceitos, e o "eu" passa a compartilhar um mundo comum de sentido. (HERMANN, 2002, p. 101).

\section{Entrelaçando alguns pontos}

Com a descrença nas metanarrativas como formas de legitimação e com as alterações técnicas na noção filosófica de verdade, a filosofia e a educação ganharam uma nova dimensão. A ação pedagógica formulada no domínio da subjetividade desloca-se para o âmbito da intersubjetividade. Isso implica em desestabilizar o arcabouço teórico do projeto pedagógico moderno. O ser humano, que foi amparado pelo Iluminismo como um ser racional, deveria conduzir um processo educacional marcado pelo otimismo na ação emancipatória e pela certeza do esclarecimento científico. Isso resultou em ênfases unilaterais, apoiadas no critério racional e no aparato tecnológico para garantir o controle e a intervenção segura sobre a natureza humana. 
É nesse horizonte que investigamos o porquê a Pedagogia e a Educação se concentraram, conforme denuncia Hannah Arendt, nos aspectos metodológicos do ensino e deixaram de lado a matéria. Ora, esta opção está em consonância com o problema da própria modernidade, que apostou na razão instrumental e técnica, priorizando o que ela pode ter de "controle" do real, isto é, na questão metodológica do processo, na busca da planificação de tudo. Ensinar e aprender envolvem elementos subjetivos, que não podem ser objetivados, e daí advém o problema da reificação. A questão da formação do professor foi ficando à deriva desse processo justamente por conta desta mesma inversão produzida pelo discurso da ciência da educação, que se afasta, não só de uma preocupação cognitiva, mas principalmente de uma visão formativa. Então, o problema da educação norte-americana pode ser vislumbrado hermeneuticamente na busca da unidade do discurso da ciência, que pretendia racionalizar tudo, transformando o ensino em técnica e método.

A hermenêutica impõe limites à descrição estrutural do sujeito, uma vez que ela se dá na lógica do acontecimento. Nesse sentido, ela quer mostrar a impossibilidade da formação de professores seguir o caminho metafísico do conhecimento como descrição de estruturas dadas objetivamente, pois isso seria negar a historicidade que nos é constituída. Em contrapartida, o paradigma da linguagem fornece um arsenal produtivo indispensável para pensar a formação de professores, na medida em que abre horizontes para além do modelo objetivante do conhecimento, servindo-nos de guia na revisão de propostas subjacentes às teorias educacionais e às práticas pedagógicas contemporâneas. A virada linguística se constitui exatamente na mudança para um novo entendimento sobre o papel da linguagem, de modo que não temos o controle que pensávamos ter sobre o mundo.

Dessas colocações, a relação teoria e prática na formação de professores não pode ser pensada segundo o modelo representacional de objetos. Operando pela perspectiva intersubjetiva, podemos destacar que o processo educativo pode provocar nos interlocutores envolvidos o estranhamento das práticas pedagógicas enrijecidas pelo paradigma unidimensional do mundo moderno. Acreditamos que o educador pela via intersubjetiva, pode desencadear a formação de uma sociedade mais humanizada, voltada para a produção de um mundo comum a todos, como almejava Hannah Arendt. 
Daí a necessidade de deixar que os próprios sujeitos em formação digam a palavra (a palavra da ciência, do ético, do estético, da dor, da poesia), radicalizando a ideia de que o homem possui linguagem. A abertura de horizontes que a linguagem oferece permite à educação promover a polissemia dos discursos na formação de professores e criar um espaço de compreensão mútua entre os envolvidos.

\section{Referências}

ARENDT, H. A crise na educação. In: . Entre o passado e o futuro. São Paulo: Perspectiva, 1992.

. Responsabilidade e Julgamento. São Paulo: Companhia das Letras, 2004.

ALVES, A. J. O planejamento de pesquisas qualitativas em educação. Cadernos de Pesquisa. São Paulo, São Paulo, v. 77, p. 53-61, Maio. 1991. . Relevância e aplicabilidade da pesquisa em educação. Cadernos de Pesquisa, São Paulo, n. 113, p. 39-50, Jul. 2001.

DEVECHI, C. V.; TREVISAN, A. L. Sobre a proximidade do senso comum das pesquisas qualitativas em educação: positividade ou simples decadência? Revista Brasileira de Educação, Rio de Janeiro, v. 15, n. 43, p. 148-161, jan./abr. 2010.

GADAMER, H.-G. A razão na época da ciência. Rio de Janeiro: Tempo Brasileiro, 1983.

. Verdad y metodo I: Fundamentos de una hermenéutica filosófica.

6. ed. Salamanca: Sígueme, 1996.

GATTI, B. A. A construção da pesquisa em educação no Brasil. Brasília: Plano, 2002.

HABERMAS, J. Pensamento Pós-Metafísico. Estudos Filosóficos. Rio de Janeiro: Tempo Brasileiro, 1990.

HERMANN, N. Pluralidade e ética em Educação. Rio de Janeiro: DP\&A, 2001.

. Hermenêutica e Educação. Rio de Janeiro. DP\&A, 2002. 
TREVISAN, A L. Terapia de Atlas: pedagogia e formação docente na pósmodernidade. Santa Cruz do Sul: EDUNISC, 2004.

WELLER, W. A Hermenêutica Como Método Empírico de Investigação. In: REUNIÃO ANUAL DA ANPED, 30ª 2007, Caxambu. Trabalhos... Disponível em: < www.anped.org.br/reunioes/30ra/trabalhos/GT17-3288-Int.pdf $>$. Acesso em: 27 ago.2009.

Data de registro: 01/12/2009

Data de aceite: 20/10/2010 